\title{
Asbestosis: assessment by bronchoalveolar lavage and measurement of pulmonary epithelial permeability
}

\author{
AR GELLERT, JA LANGFORD, RJD WINTER, S UTHAYAKUMAR, G SINHA, \\ RM RUDD
}

From the London Chest Hospital, London

ABSTRACT Thirty two patients with asbestosis were assessed by means of bronchoalveolar lavage (27 patients) and the half time clearance from lungs to blood ( $T^{1 / 2} \mathrm{LB}$ ) of an inhaled aerosol of diethylenetriamine pentacetate (DTPA) labelled with technetium $99 \mathrm{~m}$ ( 32 patients). T $1 / 2$ LB was also measured in 20 non-smoking normal individuals and 17 smokers without a history of exposure to asbestos. Thirteen patients $(46 \%)$ showed an increase in the percentage of neutrophils with or without an increase in the percentage of eosinophils and eight (29\%) showed an increased percentage of lymphocytes. The number of neutrophils plus eosinophils expressed as a percentage of the total count was positively correlated with the length of the history of disease $(r=0.53$, $\mathrm{p}<0.025$ ) and greater percentages were associated with more severe impairment of lung function. Smokers had lower percentages of lymphocytes than non-smokers $(p<0.002)$ and showed increased proportions of neutrophils and eosinophils more often than non-smokers $(p<0.05)$. In 18 non-smokers with asbestosis the mean $\mathrm{T}^{1 / 2} \mathrm{LB}$ was 33.8 (range 10.0-62.0) minutes, significantly less than $57.2(30.5-109)$ minutes in 20 non-smoking normal subjects $(p<0.002)$. In nonsmokers shorter $\mathrm{T} 1 / 2 \mathrm{LB}$ correlated with a longer time since first exposure to asbestos $(\mathrm{r}=-0.65$, $p<0.005)$, longer duration of exposure $(r=-0.70, p<0.001)$, and a shorter time since last exposure $(r=0.59, p<0.01)$. Shorter $T 1 / 2$ LB was also associated with increased inflammatory activity as shown by higher bronchoalveolar lavage cell counts $(r=-0.53, p<0.025)$ and higher combined percentages of neutrophils, eosinophils, and lymphocytes $(r=-0.47, p<0.05)$. The techniques of bronchoalveolar lavage and measurement of inhaled solute clearance may be useful in assessing inflammatory activity in asbestosis.

Asbestosis is a progressive disease leading to disability and reduced life expectancy. By the time clinical and radiological features of asbestosis are established drug treatment is usually ineffective. Consequently, the main thrust of research into asbestosis has been directed towards epidemiological studies with the aim of preventing the disease. Although strict precautionary measures are now required for asbestos workers in the United Kingdom, many people continued to have heavy exposure to asbestos until the late 1960s and in some cases the early 1970 s and a substantial number of new cases is likely to appear for the next 20 years or more. In

Address for reprint requests: Dr RM Rudd, London Chest Hospital, London E2 9JX.

Accepted 28 January 1985 countries, notably South Africa, where protective measures during the mining and handling of asbestos are still inadequate, the problem will be even greater.

It may be worth considering formal trials of antiinflammatory treatment since the alternative is continued observation of progressive decline. An active alveolitis has been shown to precede development of fibrosis in various animal experimental models of asbestosis $^{12}$ and it has been suggested that corticosteroid treatment might be effective in patients with active alveolitis. ${ }^{3}$ There is, however, little information about the alveolitis of asbestosis or about the significance of different cell subpopulations in the air spaces in this disease.

Bronchoalveolar lavage is a relatively noninvasive means of sampling the cells associated with 
the alveolitis of interstitial lung disease. ${ }^{4}$ Differential cell counts in lavage fluid have been shown to provide information about the likely rate of progression and response to treatment in cryptogenic fibrosing alveolitis, ${ }^{5}$ a disease with many similarities to asbestosis. It is a reasonable hypothesis that information from bronchoalveolar lavage may have prognostic value in asbestosis and therefore be useful in planning trials of treatment.

Although in many cases there is little doubt about the diagnosis of asbestosis - for example, in those with well established clinical and radiological signs and a history of heavy exposure-in other cases the clinical and radiological features may be minor or atypical and the heaviness of exposure doubtful. Possibly bronchoalveolar lavage findings could be of diagnostic value in such cases.

In this study we determined lavage cell profiles and asbestos body counts in asbestosis and related them to the history of asbestos exposure, smoking history, lung function, and progression of disease. We also measured the rate of clearance of an inhaled aerosol of diethylene triamine pentacetate labelled with technetium $99 \mathrm{~m}\left({ }^{99} \mathrm{mTc}\right.$ DTPA) from lungs to blood. This is thought to be an index of pulmonary epithelial permeability ${ }^{6}$ and it has been suggested that it may provide a means of assessing the activity of interstitial lung disease. ${ }^{7}$ Little is known, however, of the relationship between permeability and cellular processes in the alveoli. We examined the relationship between permeability and alveolar inflammatory activity as reflected by lavage fluid.

\section{Methods}

\section{PATIENTS}

We studied 31 men and one woman (mean age 57, range 32-74 years) with previous occupational asbestos exposure and clinical and radiological features of asbestosis. The diagnostic criteria were previous asbestos exposure, late inspiratory crackles over the lung fields, and predominantly lower and middle zone radiographic shadowing, consisting usually of small, irregular opacities and often associated with pleural thickening or calcification. Breathlessness and finger clubbing were supporting but not obligatory features. The mean time since first exposure to asbestos was 34 (range 18-53) years, and the mean duration of exposure was 19 (range $1-43)$ years. Twenty patients had worked in the lagging industry and 12 had carried out asbestos cutting, milling, and spinning. Asbestos exposure had been heavy with no protection for most of them, including the one patient who reported only one year of exposure. Fourteen patients were current cigarette smokers and 18 were non-smokers. Nonsmokers had either ceased smoking at least two years previously or had never smoked.

Patients had attended for follow up in an asbestos screening clinic for one to 30 years and retrospective annual clinical data, including spirometric results and chest radiographs, were available, though very limited in some cases. Eighteen of the 32 patients were considered to have clubbed fingers and crackles had been audible over the lungs in all 32 cases for a mean period of eight (range 1-25) years. Twenty five patients had radiological evidence of pleural disease. Length of history of disease was defined as the time since the first appearance of clinical or radiological signs of asbestosis.

Patients were invited to participate in the study on a voluntary basis. The nature of the proposed investigations was explained and patients were told that the purpose of the study was to gather information about the type of inflammatory activity that existed in asbestosis on the basis of these investigations. Informed written consent was given by all patients and the approval of the local ethical committee was obtained.

\section{BRONCHOALVEOLAR LAVAGE}

Bronchoalveolar lavage was carried out in 27 of the 32 patients (14 non-smokers and 13 smokers). The procedure was carried out through a fibreoptic bronchoscope with three sequential aliquots of 50 $\mathrm{ml}$ of sterile normal saline at $37^{\circ} \mathrm{C}$ and the sample was prepared for total and differential cell counts as previously described. ${ }^{8}$ Manual counts of regular shaped and regular segmented ferroprotein-coated fibres were carried out on samples prepared as follows. A $20 \mathrm{ml}$ aliquot of lavage fluid was centrifuged at $300 \mathrm{~g}$ for 10 minutes, the deposit was diluted with $0.5 \mathrm{ml}$ of $0.1 \mathrm{M}$ sodium hydroxide and spun at $300 \mathrm{~g}$ for 10 minutes in a Shandon Cytospin centrifuge to make slides which were air dried and fixed in methanol. Counts per slide were standardized to 1 $\mathrm{ml}$ of fluid.

\section{CLEARANCE OF " $\mathrm{m}$ TcDTPA}

The half time clearance in minutes of ${ }^{99 \mathrm{~m}} \mathrm{Tc}$ DTPA from lungs to blood ( $\left.T^{1} 12 \mathrm{LB}\right)$ was measured in all patients. T1/2 LB was also measured in a group of 20 men with a mean age of 54 (range 40-62) years, of whom 12 had never smoked and eight had ceased smoking at least five years previously, and in a group of 17 current smokers (11 men, six women: mean age 42, range 20-62) without known exposure to asbestos. An aerosol was generated from an Acorn jet nebuliser containing $20 \mathrm{mCi}^{{ }^{99 m}}$ Tc DTPA in $4 \mathrm{ml}$ saline. The output was modified by passage through an array of stainless steel ball bearings to remove 
large particles. ${ }^{\circ}$ A cascade impactor showed that $77 \%$ of particles were less than $0.9 \mu \mathrm{m}$ and only $4 \%$ were greated than $2 \mu \mathrm{m}$ in diameter. Subjects inhaled for five minutes from the nebuliser and retained about $5 \%$ of the radioactivity. Data were collected for 15 minutes with a Siemens 37 ZLC gamma scintillation camera linked to an MDS A2 computer. Correction for background tissue activity was achieved by giving an intravenous injection of $0.5 \mathrm{mCi}{ }^{99 \mathrm{~m} T c}$ DTPA and by continuous scanning of the area between the kidneys.

\section{PHYSIOLOGICAL ASSESSMENT}

The following physiological measurements were made in all patients: $\mathrm{FEV}_{1}$, forced vital capacity (FVC) (Morgan dry spirometer), total lung capacity and residual volume (Morgan constant volume body plethysmograph), transfer factor (TLCO), transfer coefficient (KCO) (Morgan Transfer Test Model No TTC), and a progressive exercise test on a cycle ergometer with measurement of capillary blood gas tensions and oxygen consumption.

\section{CHEST RADIOGRAPHS}

Profusion of opacities on a recent posteroanterior chest radiograph was assessed by the ILO scoring system. ${ }^{9}$

\section{STATISTICAL ANALYSIS}

The Mann-Whitney U test (two tailed) was used for group comparisons of quantitative data and correlations were assessed with the Spearman rank correlation coefficient. Fourfold tables were analysed by Fisher's exact probability test (two tailed). Non-parametric statistics were used because the data were not normally distributed.

\section{Results}

\section{BRONCHOALVEOLAR LAVAGE FLUID CELL COUNTS}

The mean fluid recovery was 77 (range 50-91) ml Total and percentage cell counts are shown in figures 1 and 2 . The mean total cell count per $\mathrm{ml}$ of lavage fluid was $546 \times 10^{3}$ (range 264-1460). The mean count in smokers was 593 (264-1460), not significantly higher than $503(370-678)$ in nonsmokers. The differential cell counts showed mean percentages of 68 (18-93) for macrophages, 11 (1-47) for lymphocytes, 17 (2-68) for neutrophils, and $4(0-21)$ for eosinophils (fig 2).

In a middle aged control population including smokers lavage fluid differential cell counts in isur laboratory show up to $11 \%$ lymphocytes, up to $11 \%$ neutrophils, and up to $3 \%$ eosinophils, with the combined total of neutrophils plus eosinophils not

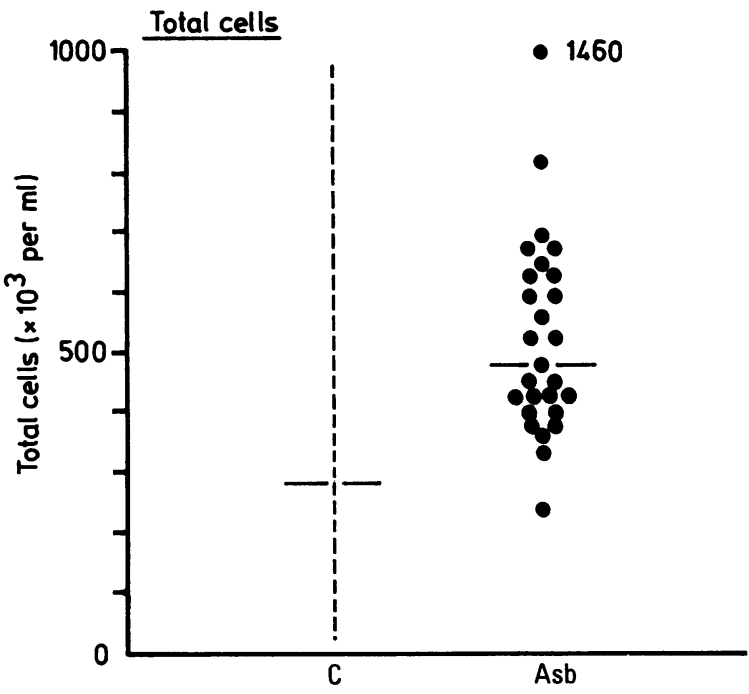

Fig 1 Total cell counts in bronchoalveolar fuid from patients with asbestosis (Asb). The range from control individuals $(C)$ in our laboratory is indicated on the left. Horizontal bars indicate median values.

exceeding $10 \%{ }^{8}$ We classified cell percentages in this study as increased if they exceeded these values. Eight patients (29\%) showed an increased proportion of lymphocytes. In one there was an associated increase in neutrophils and in another an increase in eosinophils, but the other six patients showed the highest increases in lymphocytes (range $22-47 \%$ of total cell count) without any increase in neutrophils or eosinophils. Thirteen patients $(46 \%)$ showed increases in neutrophils; of these, six had associated increases in eosinophils. Three patients (9\%) showed small increases in eosinophils alone (4\%, $6 \%$, and $6 \%$ of the differential count).

We examined the relationships between lavage fluid cell profiles and clinical features. There was no significant difference in cell profiles between patients with and without pleural disease. Percentages of lymphocytes in smokers (mean 5, range 1-14) were lower than in non-smokers (mean 18 , range $2-47)(p<0.002)$. Smokers had slightly higher percentages of neutrophils plus eosinophils than non-smokers, though these differences were not significant. When their upper limits for cell percentages, however, were compared with those of our control population, they had increased neutrophils and eosinophils, with normal lymphocytes, more often than non-smokers ( $p<0.05)$.

In the group as a whole a longer history of disease was associated with greater percentages of neutrophils plus eosinophils $(r=0.53, p<0.025)$. Because neutrophil counts tended to be higher in smokers we also considered the relationship bet- 

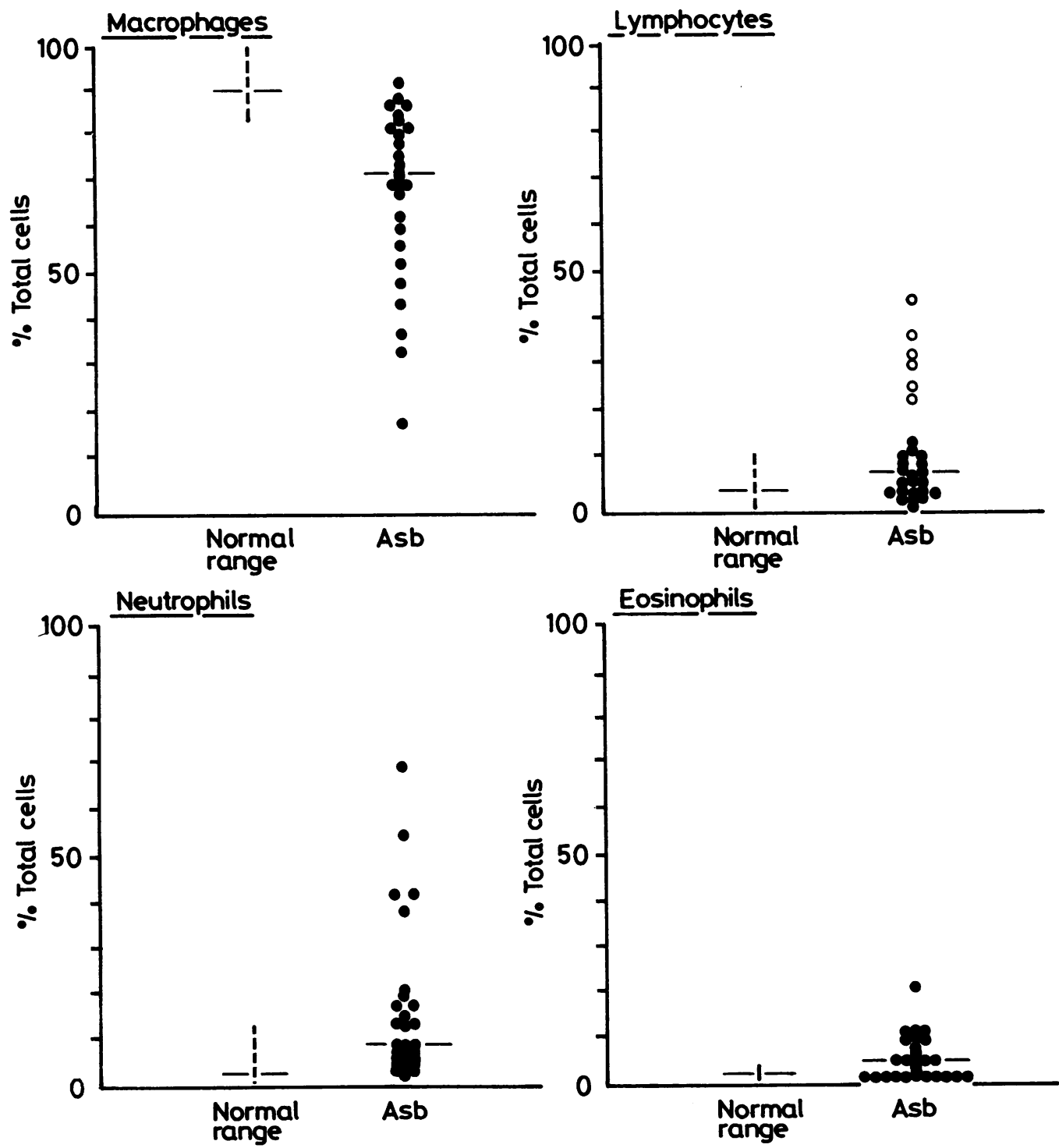

Fig 2 Bronchoalveolar fuid cell profiles in asbestosis (Asb) with normal ranges in our laboratory. Closed circles indicate results for individual patients. Open circles indicate patients with increases in lymphocytes in whom neutrophils and eosinophils were normal. Horizontal bars indicate median values.

ween length of history of disease and lavage fluid cell profile in smokers and non-smokers separately. Among non-smokers percentages of neutrophils plus eosinophils correlated with a longer history of disease $(r=0.65, p<0.025)$, but among smokers the correlation was not significant.

In the group as a whole higher percentages of inflammatory cells other than macrophages were associated with more rapid deterioration in FVC during the previous 12 months $(\mathrm{r}=0.45, \mathrm{p}<$ $0.025)$. No specific relationships between previous deterioration and individual cell types were found.

\section{ASBESTOS BODIES}

Because of delay in perfecting our method for counting asbestos bodies in lavage fluid, asbestos body 


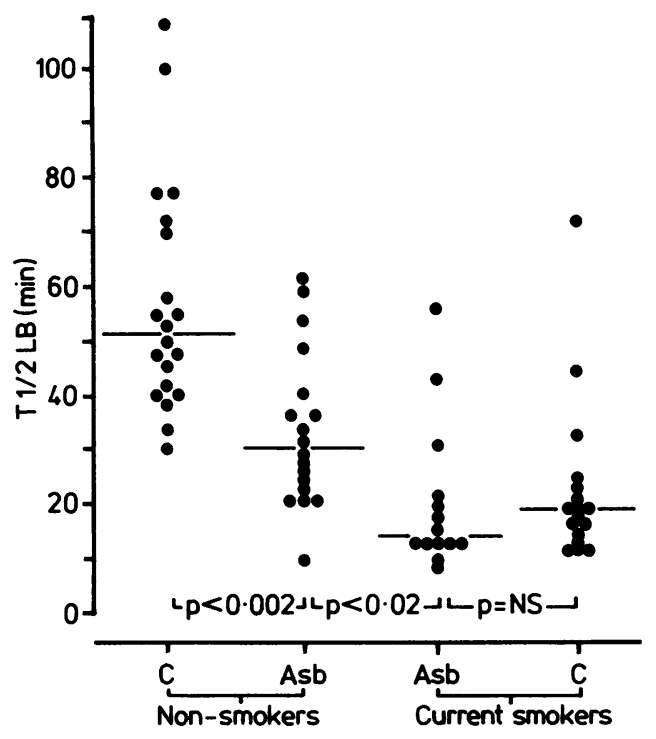

Fig 3 Half time solute clearance $(T 1 / 2 L B)$ in normal non-smokers and smokers $(C)$ and in non-smoking and smoking patients with asbestosis. Horizontal bars indicate median values.

preparations were made in only 23 cases. The mean number of bodies per $\mathrm{ml}$ of lavage fluid was 141 (15-642). Greater numbers of asbestos bodies correlated with higher percentages of macrophages $(r=$ $0.77, \mathrm{p}<0.001)$. There was a negative correlation between the time elapsed since first exposure to asbestos and the number of asbestos bodies in lavage fluid $(\mathrm{r}=-0.46, \mathrm{p}<0.025)$.

\section{CLEARANCE OF " $4 \mathrm{~m}$ Tc DTPA}

Figure 3 shows the values for $T 1 / 2 L B$ in the various groups. Mean T1/2 LB was $33.8(10.0-62.0)$ minutes in 18 current non-smokers with asbestosis, significantly less than $57.2(30.5-109)$ minutes in the 20 non-smoking control subjects $(p<0.002)$. The mean $T^{1 / 2} \mathrm{LB}$ in 14 current smokers with asbestosis was 21.2 (9.5-57.0) minutes, significantly shorter than in 18 non-smokers with asbestosis ( $p<$ 0.02 ), but not significantly different from 21.8 (11.5-68) minutes in 17 smoking control subjects.

Because of the effects of smoking on $T 1 / 2$ LB we examined the relationship of $T 1 / 2 L B$ to lavage cell profiles and other variables only in non-smokers. In non-smokers $T 1 / 2$ LB was negatively correlated with the time elapsed since first exposure to asbestos $(r=$ $-0.65, p<0.005)$, duration of exposure $(r=$ $-0.70, p<0.001$ ), percentage of inflammatory cells other than macrophages in lavage fluid $(r=-0.47$, $\mathrm{p}<0.05)$, and total cell count $(\mathrm{r}=-0.53, \mathrm{p}<$ $0.025) . T 1 / 2$ LB was positively correlated with the time elapsed since last exposure to asbestos $(r=$ $0.59, \mathrm{p}<0.01)$.

\section{LUNG FUNCTION}

Examination of the relationships between lavage fluid cell profiles and lung function variables showed an overall pattern in which higher lymphocyte percentages were associated with less severe impairment of lung function and higher neutrophil and eosinophil percentages with more severe impairment. In non-smokers a positive correlation was found between transfer factor and the percentage of lymphocytes $(r=0.66, p<0.01)$ and a negative correlation between transfer factor and the percentage neutrophils and eosinophils $(r=-0.59, p<$ 0.025 ). Relationships with lung volumes were weaker and did not reach statistical significance. In smokers no relationships were observed. No relationships were found between indices of lung function and $\mathrm{T} 1 / 2 \mathrm{LB}$.

\section{RADIOGRAPHS}

There was no correlation between profusion scores and $T^{1 / 2} \mathrm{LB}$. There was no difference in profusion scores between patients with increased lavage fluid lymphocytes and those with increased neutrophils and eosinophils.

\section{Discussion}

We have found heterogeneous bronchoalveolar lavage fluid cell profiles in asbestosis. As previously reported in small numbers of patients, ${ }^{2810^{-13}}$ we commonly identified an increase in neutrophils, but we found that this was often associated with an increase in eosinophils. In eight of our 28 cases (29\%) we observed an increase in lavage lymphocytes and in six of these cases there was no associated increase in neutrophils or eosinophils. Patients therefore tended to show either an increase in neutrophils or eosinophils (or both) or an increase in lymphocytes.

There are many similarities between asbestosis and cryptogenic fibrosing alveolitis, a disease which is also associated with heterogeneous lavage fluid cell profiles and a poor response to treatment in most cases. In asbestosis we have found that higher percentages of eosinophils and neutrophils in lavage fluid are associated with a longer history of disease, more severe impairment of lung function, and more frequent current smoking. Patients with cryptogenic fibrosing alveolitis who have increased lavage fluid neutrophils and eosinophils tend to have greater functional impairment and a longer history of disease than those with increased lymphocytes; an increase in lavage fluid lymphocytes is also associ- 
ated with responsiveness to steroids and a better prognosis, whereas an increase in neutrophils and eosinophils is associated with a greater likelihood of rapid deterioration. ${ }^{5}$ Follow up of our patients may show whether lavage fluid cell profiles in asbestosis have similar prognostic value.

Bignon and colleagues ${ }^{14}$ have shown that the number of uncoated fibres identified in lavage fluid increases with the duration of asbestos exposure but decreases with the length of time since exposure has ceased. Given that there probably is a quantitative relationship between asbestos bodies and uncoated fibres-a relationship well documented in lung tissue $^{1516}$-our finding that fewer asbestos bodies are associated with a longer time since initial exposure seems to support the findings of Bignon and colleagues ${ }^{14}$ : most of our patients experienced heavy, unprotected exposure to asbestos before precautions became mandatory for asbestos workers in the late 1960s and the time since first exposure probably reflects the time since last heavy exposure. Our findings are consistent with the suggestion that fibres are cleared from the lungs, either by the breaking up and dissolution of chrysotile or by expectoration of fibres shorter than $5 \mu \mathrm{m} .{ }^{17}$ The relationship between the number of asbestos bodies and the number of macrophages in lavage fluid may support the role of the macrophage in removing fibres from the lung.

We found that the faster the clearance of DTPA in current non-smokers the longer the time since first exposure to asbestos and the duration of exposure to asbestos and the shorter the time since the last exposure. This suggests a dose-response relationship in asbestosis, followed by recovery after cessation of exposure, observations similar to those reported during and after cessation of smoking by Minty and colleagues. $^{18}$ As expected, the already well documented effects of cigarette smoking on pulmonary epithelial permeability ${ }^{6} 19$ were confirmed by even faster clearance of solute in current smokers with asbestosis than in current non-smokers with asbestosis. Abnormalities in $T 1 / 2 \mathrm{LB}$ in ex-smokers in our study are unlikely to have been related to previous smoking because its effects diminish rapidly after cessation, ${ }^{18}$ and solute clearance is normal in ex-smokers with chronic obstructive lung disease. ${ }^{620}$ Disturbance of permeability seems to reflect inflammatory activity in lavage fluid though it is not associated with any particular cell profile. Estimation of permeability might have a role in screening patients with active disease for further study by bronchoalveolar lavage.

Apart from a possible role in assessing activity of disease in asbestosis, bronchoalveolar lavage has some diagnostic value. Details of asbestos exposure many years previously are difficult to recall, and in the absence of characteristic asbestos induced pleural changes it may be very difficult to distinguish between asbestosis and cryptogenic fibrosing alveolitis. In the presence of interstitial lung disease, the demonstration by bronchoalveolar lavage of numerous asbestos bodies within the lung tilts the balance of probabilities towards a diagnosis of asbestosis because asbestos bodies are rarely found in patients with other interstitial lung diseases; when they occur in individuals who do not have asbestosis, they do so in much smaller numbers than are seen in asbestosis. ${ }^{21}$ In cases where there is doubt about the presence of interstitial lung disease-for example, because parenchymal radiographic change is slight or obscured by pleural changes - the finding of an abnormal differential cell count in lavage fluid increases the probability that interstitial lung disease is present.

In asbestosis bronchoalveolar lavage findings are related to clinical features and to abnormalities in lung epithelial permeability. Longitudinal studies will show whether these techniques are useful in the assessment of prognosis and in the selection of patients for trials of treatment.

AG is supported by a grant from the Clinical Research Committee of the National Heart and Chest Hospitals. We thank Dr SJ Steel for his help in reading the chest radiographs and Miss B Hood for her helpful advice in interpreting the bronchoalveolar lavage preparations.

\section{Reference}

1 Schoenberger CI, Hunninghake GW, Gadek JE, Crystal RG. Inflammatory and asbestosis: characterization and maintenance of alveolitis following acute asbestos exposure. Chest 1981;80:70-1S.

2 Begin R, Cantin A, Drapeau G, et al. Pulmonary uptake of gallium-67 in asbestos-exposed humans and sheep. Am Rev Respir Dis 1983;127:623-30.

3 Crystal RG, Gadek JE, Ferrans VJ, Fulmer JD, Line BR, Hunninghake GW. Interstitital lung disease: current concepts of pathogenesis, staging and therapy. $A m$ J Med 1981;70:542-68.

4 Keogh BA, Crystal RG. Alveolitis: the key to the interstitial lung disorders. Thorax 1982;37:1-10.

5 Rudd RM, Haslam PL, Turner-Warwick M. Cryptogenic fibrosing alveolitis: relationships of pulmonary physiology and bronchoalveolar lavage to response to treatment and prognosis. Am Rev Respir Dis 1981;124:1-8.

6 Jones JG, Royson D, Minty BD. Changes in alveolarcapillary barrier function in animals and humans. $A m$ Rev Respir Dis 1983;127:S51-9.

7 Rinderknecht J, Shapiro L, Krauthammer M, et al. Accelerated clearance of small solutes from the lungs in interstitial lung disease. Am Rev Respir Dis 
1980;121:105-17.

8 Studdy PR, Rudd RM, Gellert AR, Uthayakumar S, Sinha G, Geddes DM. Bronchoalveolar lavage in the diagnosis of diffuse pulmonary shadowing. $\mathrm{Br} J \mathrm{Dis}$ Chest 1984;78:46-54.

9 International Labour Office. Guidelines for the use of ILO international classification of radiographs of pneumoconioses. Geneva: ILO, 1980. (Occupational safety and health series No 22, rev 80.)

10 Bignon J, Atassi K, Jaurand MC, et al. Cellular and protein content analysis of broncho-alveolar lavage fluid from patients with idiopathic pulmonary fibrosis and asbestosis. Rev Fr Mal Respir 1978;6:353-8.

11 Hunninghake GW, Gadek JE, Kawanami O, Ferrans VJ, Crystal RG. Inflammatory and immune processes in the human lung in health and disease: evaluation by bronchoalveolar lavage. Am J Pathol 1979;97:149206.

12 Haslam PL, Turton CWG, Heard B, et al. Bronchoalveolar lavage in pulmonary fibrosis: comparison of cells obtained with lung biopsy and clinical features. Thorax 1980;35:9-18.

13 Gadek JE, Hunninghake GW, Schoenberger CI, Crystal RG. Pulmonary asbestosis and idiopathic pulmonary fibrosis: pathogenetic parallels. Chest 1981;80:63S-4S.
14 Bignon J, Sebastien P, Gaudichet A, Bientz M. Analysis of mineral particles recovered by bronchoalveolar lavage for diagnosis of dust related lung diseases. Am Rev Respir Dis 1978;117:218 (abstract).

15 Ashcroft T, Heppleston AG. The optical and electron microscopic determination of pumonary asbestos fibre concentration and its relation to the human pathological reaction. J Clin Pathol 1973;26:224-34.

16 Fondimare A, Desbordes J. Asbestos bodies and fibres in lung tissues. Environ Health Perspect 1974;9:147-8.

17 Parkes WR. Occuptional lung disorders. 2nd ed. London: Butterworth, 1982:233-332.

18 Minty BD, Jordan C, Jones JG. Rapid improvement in abnormal pulmonary epithelial permeability after stopping cigarettes. Br Med J 1981;282:1183-6.

19 Jones JG, Lawler P, Crawley JCW, Minty BD, Hulands G, Veall N. Increased alveolar epithelial permeability in cigarette smokers. Lancet 1980;1:66-8.

20 Huchon GJ, Russell JA, Barritault LG, Murray JF. Alveolar-capillary membrane permeability (ACMP) in chronic obstructive pulmonary disease (COPD) and in smokers. Am Rev Respir 1982;125:280 (abstract).

21 De Vuyst P, Jedwab J, Dumortier P, Vandermoten G, Vande Weyer R, Yernault J. Asbestos bodies in bronchoalveolar lavage. Am Rev Respir Dis 1982; 126:972-6. 